\title{
ChAVES DE LEITURA PARA A ANÁLISE DO DISCURSO POLÍTICO SOBRE EDUCAÇÃO E EDUCAÇÃO PROFISSIONAL ${ }^{12}$
}

\author{
LECTURE KEYS FOR THE POLITICAL DISCOURSE ANALYSIS ABOUT EDUCATION AND PROFESSIONAL EDUCATION
}

\author{
Irlen Antônio Gonçalves*
}

irlen@cefetmg.br

RESUMO: Esse texto discute sobre possíveis chaves de leitura para a análise do discurso político sobre educação e educação profissional na virada do século XIX para o século XX. O discurso político será considerado como prática de linguagem que medeia a relação entre o sujeito e a sua realidade natural e social constituindo-o e à sua história. Dessa forma, tal discurso visava intervir na vida social, com vistas a produzir novos comportamentos, sensibilidades e expectativas. A discussão conceitual dialoga com aportes da História Política, da História dos Conceitos e da História da Linguagem. Do ponto de vista metodológico, propomos uma análise que privilegia os discursos como portadores e constituintes de uma representação de sociedade, de sujeitos, de estratégias, enfim de uma realidade social inspirada nos referencias da análise do discurso político proposta por Patrick Charaudeau. Dentro dessa perspectiva, apresentaremos as seguintes chaves de leitura: formação/profissão, geração e pertencimento familiar.

PalaVRas Chave: História da Educação, sujeito do discurso, discurso político.

ABSTRACT: This essay discusses about possibles lectures keys for the analysis of political discourse about education and professional education on the turn of the 19th century to 20th century. The political discourse will be considered as a language practice that mediates the relationship between subject and its natural and social reality constructing them and their story. In this manner, given discourse aimed to intervene on social life, with the objective of producing new behaviors, sensibilities and expectations. The theoretical discussion dialogues with the approaches of Political History, Concepts History and Language History. On the methodological standpoint, we propose an analysis that privileges the discourses as bearers and builders of a representation of society, subjects and strategies with the view of a social reality inspired on the references of political discourse analysis proposed by Patrick Charaudeau. Inside this perspective, we present the following lecture keys: formation/professio, generation and familiar belonging.

KEYWORDS: History of Education, subject of discourse, political discourse.

\section{Introdução}

O que vamos tratar neste texto, num sentido mais geral, diz respeito às possiblidades teórico-metodológicas de análise de fontes documentais, ou seja, textos escritos, testemunho e discurso. Especificamente, o nosso intento é o de apontar algumas

\footnotetext{
${ }^{1}$ Esse texto representa o esforço de sistematização teórico-metodológica do investimento que o autor tem desenvolvido para analisar documentos históricos que tratam da Educação Profissional como objeto de pesquisa no campo da História da Educação. Tal investimento vincula-se à pesquisa que venho desenvolvendo nos últimos anos, sobre o discurso dos legisladores sobre a educação profissional, a partir das políticas públicas que visam intervir na vida social do trabalhador.

${ }^{2} \mathrm{O}$ meu agradecimento especial à professora Vera Lúcia Nogueira, pela leitura atenta, pelas críticas e pelas boas sugestões, as quais foram incorporadas no texto.

* Doutorado em Educação pela Universidade Federal de Minas Gerais (2004). Atualmente é professor do Centro Federal de Educação Tecnólogica de Minas Gerais - CEFET-MG.
} 
chaves de leitura úteis ao historiador que se dedica à análise do discurso político dos mediadores das políticas públicas na virada do século XIX para o século XX. Tal discurso, visava instituir os espaços de formação do trabalhador nacional, tendo na implementação de reformas da educação, e da educação profissional, a centralidade de proposições que interviriam na vida social, com vistas a produzir novos comportamentos, sensibilidades e expectativas.

Partimos do entendimento de que as questões de cunho metodológico precisam ser acompanhadas por abordagens teóricas auxiliadoras do conhecimento acerca do diálogo com o texto e o seu discurso, no caso aqui em tela, com as fontes documentais que produziram um discurso sobre a educação profissional. Nessa perspectiva, propomos uma análise que privilegia os discursos como portadores e constituintes de uma representação de sociedade, de sujeitos, de estratégias, enfim de uma realidade social.

Partindo, por exemplo, de uma compreensão do discurso de forma ampliada, refletimos com Barros quando ele faz uso da compreensão de Michel Foucault "de que não é a sociedade que constitui a realidade, mas sim os discursos que ela produz" (BARROS, 2005, p. 135). Desse modo, quando nos debruçamos sobre o estudo da educação profissional em Minas Gerais, estudamos o que a fonte nos diz sobre essa educação, ou seja, estudamos a fonte que produziu um discurso sobre a educação profissional.

Assim, para atender ao objetivo aqui proposto, antecedido por uma problematização das fontes históricas, estabelecemos um diálogo conceitual com referências da análise do discurso ${ }^{3}$ e da análise do discurso político de influência francesa ${ }^{4}$, de modo a subsidiar a proposição das chaves de leitura. Com isso, organizamos este artigo em três seções: na primeira, apresentamos uma discussão conceitual sobre fonte, texto e discurso. Na sequência, apresentamos uma abordagem acerca do discurso político e, por fim, mobilizando os conceitos, previamente discutidos, nos debruçamos sobre um conjunto de fontes relativas à educação e educação profissional ${ }^{5}$ em Minas Gerais, apresentando,

\footnotetext{
${ }^{3}$ Não estamos aqui propondo uma análise do discurso "clássica" do campo epistemológico da Análise de Discurso (AD), mas uma abordagem da História da Educação ancorada pelos aportes desse campo.

${ }^{4}$ Dominique Maigueneau (2013); Patrick Charaudeau (2008).

5 As expressões educação e educação profissional estão sendo tomadas, neste texto, de forma geral de maneira a contemplar as ações relativas as proposições de políticas de escolarização. Na virada do século XIX para o século XX a educação relacionava-se a instrução e a educação profissional ao ensino profissional.
} 
assim, as chaves de leitura para análise do discurso político do senador Virgílio Martins de Mello Franco.

A fonte que nos prende é a de texto escrito, o qual nos traz o discurso, que é político

Não é demais começar afirmando que a fonte é uma escolha necessária do historiador. E uma vez escolhida, e sendo tomada como discurso, a atenção precisará ser dada aos passos que, nessa escolha, estarão imbricados: a identificação da sua procedência, a sua inserção na vida social, as condições de sua produção e a formulação das perguntas (BARROS, 2005). Isso nos leva, preliminarmente, a explicitar o que compreendemos ser uma fonte histórica. Assim, apropriando-nos da conceituação concebida por José D'Assunção de Barros, ao problematizar as relações entre a História política, o discurso e imaginário, consideramos como fonte "aquilo que coloca o historiador diretamente em contato com o seu problema" (BARROS, 2005, p. 131). É, grosso modo, o material produzido pela humanidade no tempo e espaço que representa a herança do passado disponível para se construir o conhecimento histórico. Acrescenta-se que é o material "por meio do qual o historiador examina ou analisa uma dada realidade social humana no tempo", um sujeito ou sujeitos numa dada espacialidade e temporalidade históricas. (BARROS, 2005, p. 131),

Assim, uma fonte pode preencher as funções de testemunho e de discurso: como testemunho, "ela é o meio de acesso àqueles fatos históricos que o historiador deverá reconstruir e interpretar (fonte histórica = fonte de informações sobre o passado)", ou ela mesma como discurso, sendo "o próprio fato histórico" construído e constitutivo no seu conteúdo. Nesse último caso, estou considerando que a fonte, para além do texto, está sendo tomada como "objeto de significação" e "objeto de comunicação cultural entre sujeitos", por isso discurso (BARROS, 2005, p. 131).

Os dois aspectos, "objeto de significação" e "objeto de comunicação cultural entre sujeitos", apontados por Barros (2005), são complementares, e ainda acrescento que são indissociáveis, pois definem o texto-discurso pela sua organização ou estruturação tornandoo uma "totalidade de sentido" e um "objeto de comunicação". No primeiro caso, segundo o autor, a análise é interna ao texto e poderá ser desenvolvida pelos aportes teóricometodológicos de várias abordagens, dentre os quais destaco a Semiótica, a Linguística, a História da Linguagem e do Pensamento e do Ideário Político, a Análise do Discurso Político, dentre outros. No segundo, ele aponta que a análise é externa ao texto e remete às 
abordagens do contexto social que o envolvem e the conferem sentido. Ainda, podemos destacar o exame do ponto de vista das "intenções ou das motivações" da produção do texto e daqueles/as que são atinentes ao autor que o produziu e lhe conferiu sentido (IDEM, 2005, p. 132). Nesse caso, vale a menção da abordagem da contextualização linguística que gravita em torno da Filosofia da Linguagem, da Ciência Política e da História Intelectual e História da Linguagem.

Além dos aspectos mencionados, o historiador, aqui na condição de analista do discurso, poderá contemplar outras dimensões pertinentes ao texto-discurso, que são: o "intratexto", o "intertexto" e o "contexto". Segundo Barros, o intratexto "corresponde aos aspectos internos", com implicações na avaliação do texto como objeto de significação; o intertexto diz respeito ao relacionamento do texto com outros textos; e o contexto tem a ver com a relação do texto com a realidade sócio histórica que o "produziu e que o envolve". (IDEM, 2005, p. 132). São as duas últimas dimensões que exigem o tratamento do texto como objeto de significação em si, considerando-o como objeto de comunicação. Em síntese, estamos considerando que essas são as três dimensões que corroboram para o estudo do discurso textual como fonte.

Dando ênfase ao contexto, temos que assumir que

todo texto é produzido em um lugar que é definido não apenas por um autor, pelo seu estilo e pela sua história, mas principalmente por uma sociedade que o envolve, pelas dimensões desta sociedade que penetram o autor e, através dele, no texto", sem que disto ele necessariamente se perceba. (BARROS, 2005, p. 133).

Essa afirmação faz eco ao que Eni Puccinelli Orlandi considera como "historicidade do texto" (ORLANDI, 1995, p. 112) e que tem a ver com a materialidade histórica e, por conseguinte, com a implicação na produção de sentidos do texto. Compreendido desta forma, afirma a autora que "o texto pode ser [...] atravessado por várias formações discursivas", isso porque, na sua historicidade estão presentes muitos sujeitos, posicionados historicamente em determinadas temporalidades específicas, nas quais ao produzir o sentido do texto, "o sujeito se produz, produzindo sentidos" (IDEM, 1995, p. 113-114). Desse modo, não seria inoportuno afirmar que o texto é um objeto histórico pelo menos por duas razões: porque é ele um discurso e porque é ele produzido numa temporalidade específica. 
Assim, na leitura de textos políticos, na compreensão da produção do conhecimento histórico, o texto adquire, além da sua função de ser discurso, também uma função de documento. Documento, conforme Jacques Le Goff, "não é qualquer coisa que fica por conta do passado, é um produto da sociedade que o fabricou segundo as relações de força que aí detinham o poder" (LE GOFF, 1992, p. 545).

Adquirindo, portanto, a sua função de discurso e de documento, o texto precisa ser também percebido e captado nos vários constrangimentos que estão contidos em seu contexto. Referimo-nos, entre outros, à sua autoria, ao público a que se destina, ao lugar de seu pronunciamento, à sua linguagem, às suas intencionalidades. Inclui-se que a sua produção se deu numa determinada época, numa sociedade específica com suas singularidades, num ambiente social, que pode ser rural, urbano, fechado, aberto, com público seleto ou diverso, numa instituição com seus ritos, mitos, valores, regras, uma linguagem e uma língua codificadas e com regras determinadas para o uso da mídia comunicacional. Tudo isso presente no texto, compondo a sua função discursiva. (BARROS, 2005)

Importa ainda destacar que tais constrangimentos fazem parte dos poderes que atuam sobre o autor do texto, mas também são por ele considerados e apropriados como elementos para, no texto, elaborar o seu discurso. Outra questão, não menos importante, trata do "para quem" o texto e seu discurso se destinam. Mais especificamente, o receptor ou grupos de receptores, que podem ser os leitores, os agentes também investidos de poderes, como os pares que no mesmo âmbito decidem, pessoas que irão sofrer a ação do produtor do discurso, públicos em geral etc.

Mediante tais considerações, é oportuno o destaque da necessária habilidade que deve ter o historiador ao lidar com a análise do texto-discurso, sobretudo atento ao que Barros sintetizou como "vértices" da comunicação: o "lugar de produção", afeto à temporalidade onde foi produzido, o "conteúdo", que diz respeito à intenção, à mensagem e ao "lugar de recepção", que se refere a quem se destina o discurso (BARROS, 2005, p. 134). Pode-se acrescer a tais vértices, com intuito de chamar a atenção para a compreensão do texto como rede de significação, a "intertextualidade", que inclui os outros textos que são chamados para a produção da narrativa textual, explicitados ou não pelo autor, com vistas a cumprir o papel discursivo, mas também para outros aspectos que, em muitos casos, irão 
compor o gênero no qual irá se enquadrar o texto. Estamos falando, por exemplo, em produção de normas (como produto, mas também como processo, sobretudo no que diz respeito à sua função de intervir na vida social, das pessoas, das instituições e nos vários segmentos da sociedade de maneira geral) e em repertórios que regulam o gênero posto à análise (IDEM, 2005).

A intertextualidade pode também ter mão dupla quando se examina ou analisa um texto como discurso. Da mesma maneira como ela está presente no texto analisado, está também no autor que o analisa. Isto porque, é quase consenso de que quando se analisa um texto, "não se analisa jamais um texto: analisa-se pelo menos dois". (VERÓN, 1992, apud BARROS, 2005, p. 134).

\section{O texto e o discurso contêm história e historicidade}

Ao historiador que se debruça sobre o discurso político, uma distinção conceitual que se faz oportuna refere-se ao que estamos considerando como texto e discurso, pois, embora interrelacionados, não são a mesma coisa. Com os estudos da linguística textual, temos que um texto, para ser considerado como tal, precisa conter uma textualidade, sendo essa uma derivação de um discurso que a sustenta, dentro de uma compreensão de um comunicado significativo. Acrescenta-se que na textualidade se encontram os elementos que compõem a unidade sociocomunicativa, a semântica e o formal (ORLANDI, 1995; COSTA VAL, 1991). A partir das considerações de Maria da Graça Costa Val, temos o entendimento de que o primeiro dos elementos - a unidade sociocomunicativa - refere-se ao "funcionamento do texto na sua atuação informacional e comunicativa", incluídas as peculiaridades de cada ato de comunicar: intenções de quem o produziu, os jogos de imagens mentais e a perceptibilidade auditiva e visual. O segundo elemento - a semântica é o que dá ao texto a sua coerência, isto é, o que nele subjaz, o sentido do ato de comunicar. Aqui, além dos aspectos lógicos e semânticos estão também os cognitivos, uma vez serem dependentes "do partilhar de um dado conhecimento". Os elementos formais, são aqueles que fazem com que o texto, na sua coesão, tenha o significado partilhado entre o que fala (escreve) e o que ouve (ler) (COSTA VAL, 1991, p. 4-5). Falamos, então, sobre o que o texto contém de signos propiciadores (aqueles que fazem parte das normas reguladoras da língua e de seu uso, mas também aqueles que remetem para os conceitos que são partilhados) (IDEM, 1991). 
Tais considerações dizem respeito ao texto enquanto uma unidade sócio histórica que traz em si formações discursivas que visam operar a comunicabilidade. O texto e, assim, o discurso que nele está contido é uma produção muito além e para além de si mesmo, uma vez fazer parte de um processo muito mais amplo e extenso de construção que se forma antes mesmo de sua existência. Por isso, o texto e o discurso contêm história e historicidade. Queremos chamar a atenção para todo o conjunto implicado na análise de um texto, que a princípio traz em si ou encerra em si uma fonte empírica datada, mas cuja formulação dependeu de uma série de situações culturais, sociais, econômicas e históricas.

Um texto com seu discurso, como objeto e fonte de pesquisa, é uma construção histórica que não pode ser tomado sem a consideração de que a sua formulação se deu na longevidade do tempo e que o seu sentido e significado fazem parte de um todo maior processado numa dada realidade, que veio se constituindo lenta e progressivamente dentro de um cenário de experiências e expectativas que incluem os sujeitos e situações que não podem ser ignoradas. O que quero dizer é que a produção do texto e o discurso que nele está contido têm uma complexidade que exige do historiador muita atenção. Essa complexidade pode ser pensada, por exemplo, à luz do par conceitual proposto por Reinhart Koselleck: "espaço de experiência" e "horizonte de expectativa" (KOSELLECK, 2006).

Por um lado, o discurso de modo geral é produzido na e pela experiência de um dado sujeito, que também inclui a experiência de outros sujeitos. A experiência remete para um conjunto amplo e diversificado de situações que incluem os elementos constitutivos da língua e da linguagem, o processo de socialização dos conhecimentos, do ato de comunicação, a origem social dos sujeitos, dos que produziram o discurso e dos que dele socialmente partilharam. São situações que se encontram presentes no discurso.

Por outro, o discurso, como ato comunicacional, propõe de alguma maneira algum efeito ou alguma intervenção sobre uma dada situação, aqui pensando com Foucault, que o entende não somente como algo puramente linguístico, mas como prática para intervir. Assim, o discurso tem o alcance de um horizonte de expectativa.

Tendo, assim, problematizado as distinções entre texto e o discurso, nos interessa ressaltar e propor que o historiador analise não o texto em si mesmo, mas o discurso que nele está contido, tal como nos adverte Eni Orlandi ao afirmar que: 
não é sobre o texto que falará o analista, mas sobre o discurso. Uma vez atingido o processo discursivo, que é o que faz o texto significar, o texto, ou os textos particulares analisados desaparecem como referências específicas para dar lugar à compreensão de todo um processo discursivo do qual eles - e outros que nem mesmo conhecemos - são parte. (1995, p. 117).

Tendo feito, portanto, uma apresentação dos conceitos que têm subsidiado nossas análises acerca dos discursos políticos referentes às políticas públicas educacionais, restanos, ainda, problematizar o que estamos considerando como discurso político e como tratálo metodologicamente, o que será tratado na sequência deste artigo.

\section{O discurso político como prática de intervenção social}

O que torna um discurso, um discurso político? Partimos do entendimento de que o político é, em primeira mão, a procedência do discurso, embora pudessemos falar de outras procedências que poderiam ser, por exemplo, o lócus onde se encontra depositado o texto ou onde se encontra a sua guarda. A pergunta a ser feita à fonte, nesse caso, seria, então: de onde vem o texto? Outras procedências poderiam ser, ainda: um texto manifesto de uma dada pessoa, grupo de pessoas, instituição; um texto de um discurso de um candidato a um cargo público; de um discurso de membros de partidos políticos, de membros do Executivo, do Legislativo; os Anais da Câmara ou do Senado; os jornais; os relatórios etc.

Outro procedimento, também necessário diz respeito ao conteúdo que prende o analista, sobretudo quando o texto se apresenta mostrando algo que pode ser considerado agradável ou desagradável, ou mesmo, uma interessante narrativa. Sem entrar em minudências, poderíamos então, lançar outras indagações que auxiliaram a perscrutar a internalidade do texto, tais como: com quem está falando? De que fala? Por que fala? O que oculta ou silencia? Onde quer chegar? Que poderes exerce, e que poderes lhe atravessam? Trata-se de um alerta para não se incorrer na armadilha da ocultação daquilo que poderá estar no entredito, no interdito ou mesmo no não dito 6 . Tais indagações nos remetem à dica dada por Carlo Ginzburg sobre o paradigma indiciário, quando propõe a busca das pistas, das evidências, dos rastros, sinais e indícios. Para ele, "é necessário examinar os pormenores mais negligenciáveis" (GINZBURG, 1989, p. 144). De outro modo, a atenção também precisará estar nas possíveis contradições do texto, "seja no nível do intratexto" (no seu

\footnotetext{
${ }^{6}$ A esse respeito, sugiro ver: Orlandi, 1995.
} 
interno), ou "no do intertexto (no confronto com os outros textos presentes ou mesmo no possível contraste com outras fontes)" (BARROS, 2005, p. 135).

Ademais, também refletindo com Foucault (2000), poderíamos dizer, por exemplo, que as informações que se colhem do texto sobre o corpo, a sexualidade, a loucura, a economia, a vadiagem, a delinquência são discursos sobre, pois foi a fonte, que contém o texto do discurso, que assim os ordenou, classificou, representou. O corpo da fonte é o discurso sobre o corpo, e não o corpo em si mesmo. O vadio da fonte, da mesma maneira, não é o vadio, é o discurso sobre o vadio. O vadio não existe por si só! Em seu livro, "A ordem do discurso", Foucault, ao enunciar os princípios da exclusão e da interdição, irá nos alertar que:

em toda sociedade a produção do discurso é ao mesmo tempo controlada, selecionada, organizada e distribuída por certo número de procedimentos que têm por função conjurar seus poderes e perigos, dominar seu acontecimento aleatório, esquivar sua pesada e temível materialidade $(2000$, p. 8 e 9$)$.

Enfim, desenvolver o exercício da pesquisa sobre o discurso impende a compreensão do que seja o discurso político. Assim, o ponto de partida é compreendê-lo como portador e constituinte de representação de sociedade, de sujeitos, de estratégias, enfim de uma dada realidade social. Tal entendimento, nos leva a considerar o discurso como prática de linguagem que medeia a relação entre o homem, a mulher, e a sua realidade natural e social, constituindo-o (a) e à sua história. Além disso, e por isso, considera que todo discurso se processa a partir da condição de sua produção como linguagem, como um objeto sócio histórico, dimensionado no tempo e no espaço das práticas do humano (ORLANDI, 2001). Dessa forma, o discurso aqui está sendo compreendido como prática do social.

Avançando em nossas considerações, com Patrick Charaudeau temos que o "ato de linguagem está ligado à ação mediante as relações de força que os sujeitos mantêm entre si, relações de força que constroem simultaneamente o vínculo social" (CHARAUDEAU, 2008, p. 17). A partir disso, é possível afirmarmos que a linguagem e a ação são indissociáveis, mas, ao mesmo tempo, dependentes do tempo histórico em que se dão ou em que se deram. A compreensão de qualquer discurso como linguagem dependerá do conhecimento dos sujeitos que os produziram, do seu tempo de produção e de suas finalidades para intervir na vida social. Assim, o discurso de um deputado ou senador, no ambiente legislativo, pode ser 
tomado como uma ação política efetiva que tem, ou tinha, como fim a organização da sociedade por meio da intervenção da lei, ou seja, de um ordenamento legal.

Como abordagem teórica para o adensamento do diálogo com as fontes nas quais se localiza o discurso político, ressaltamos a importância do aporte da História Política. Particularmente, um dos autores que vimos mobilizando em nossas pesquisas, para esse diálogo é o historiador Serge Berstein, especialmente quanto à sua elaboração do conceito de cultura política. Com ele, temos que o movimento para a identificação da cultura política é duplo: primeiramente pelo discurso, pelo argumentário e pelo gestual. $\mathrm{O}$ discurso é o pronunciamento oral ou escrito, elaborado com uma série de significados que expressam a maneira de pensar e de agir de um indivíduo dirigindo-se ao outro ou a um grupo de indivíduos. Nele, se encontram os elementos simbólicos comunicacionais. O argumentário é o conjunto dos argumentos constitutivo do discurso. E o gesto é a expressão da forma como o discurso é manifesto, seja com movimentos corporais, caso ocorra na oralidade, seja pelo uso de uma linguagem ou de um repertório argumentativo expresso com variados sentimentos, intenções, analogias e metáforas, tais como as maneiras de se comunicar por meio de correspondências escritas que vão variar de acordo com a relação estabelecida entre quem comunica e quem receberá a comunicação. Por exemplo, quando alguém se dirige a um conhecido, com aproximações de amizade ou inimizade, manifestando-se com a expressão de consideração, afeto, cordialidade ou de raiva, decepção e até ódio. Outro exemplo, quando o discurso ganha o espaço da formalidade e da informalidade, o que se diferenciará na relação entre os indivíduos que se comunicam. Esse discurso, composto de um repertório de argumentos e expresso em gestos, possibilitará a identificação da filiação e das raízes do indivíduo, seja ele de origem política, religiosa ou de outras que fazem parte das suas intencionalidades.

O segundo movimento, de captura da cultura política, é o que reflete a dimensão coletiva dos indivíduos. Esse, segundo Berstein (1998, p. 361), "fornece uma chave que permite compreender a coesão de grupos organizados à volta de uma cultura". Um grupo que se constitui na comunhão de seus membros, "com visão comum do mundo, numa leitura partilhada do passado, de uma perspectiva idêntica de futuro, em normas, crenças, valores que constituem um patrimônio indiviso, fornecendo-lhes, para exprimir tudo isto, um vocabulário, símbolos, gestos". (BERSTEIN, 1998, p. 361 - 362). Assim, a cultura política, 
como uma categoria de análise histórica, auxilia na compreensão das "motivações dos atos dos homens num momento da sua história, por referência ao sistema de valores, de normas, de crenças que partilham, em função da sua leitura do passado, das suas aspirações para o futuro, das suas representações da sociedade (BERSTEIN, 1998, p. 362).

Posto dessa maneira, não tem como analisar o discurso político sem conhecer o sujeito do discurso, conhecer o processo de sua produção, pois ele é realizado por sujeitos posicionados numa determinada temporalidade e inserido numa dada vida social. No caso do tempo, o rigor da análise histórica nos leva ao entendimento de que qualquer discurso não pode ser apreendido desencarnado de sua historicidade, pois a sua produção se deu num tempo específico com todas as repercussões e contradições próprias da complexa realidade onde se deu. De igual maneira, os sujeitos dos discursos precisam ser considerados, uma vez que trazem consigo as marcas da sua história de vida, a de sua formação, o seu pertencimento geracional, o grupo que se filia e, também, no âmbito da individualidade, as suas idiossincrasias. Assim, nosso entendimento é o de que estudando o sujeito, torna-se possível averiguar o protagonista dos discursos políticos, com quem interage, seu pertencimento familiar, formação e envolvimento na vida social.

\section{Chaves de leitura para a análise do discurso político}

Feitos alguns esclarecimentos teóricos e conceituais, passamos à apresentação dos procedimentos que será adotado para a análise dos discursos políticos proferidos pelo senador Virgílio Martins de Mello Franco, no Congresso Legislativo de Minas Gerais, na primeira legislatura após a Proclamação da República (1891-1895).

$\mathrm{Na}$ análise do discurso político, consideramos central o conhecimento acerca do sujeito do discurso, uma vez que será por meio desse conhecimento que iremos captar o processo de como o discurso político foi produzido. Para isso, elegemos como preponderante as seguintes chaves de leitura: formação acadêmico-profissional, às relações de solidariedade geracional e à origem do pertencimento familiar.

\section{Formação/profissão}

A chave de leitura formação/profissão tem em vista elucidar a origem da formação acadêmico-profissional do sujeito do discurso, com a intenção de captar o conteúdo dos seus discursos, uma vez que concebemos, como afirmado por John Greville Agard Pocock 
(2003), o discurso como linguagem, que tem a sua origem nas práticas institucionais da sociedade, com forte influência dos discursos produzidos no interior do seio onde se formou. Nesse caso, os discursos políticos carregam consigo os lugares de formação de seus sujeitos e de sua profissionalização, exercidos no âmbito de sua legitimidade profissional, seja de juristas, de médicos, engenheiros ou mesmo de outra área profissional.

No caso aqui considerado, o discurso político se institucionalizou num lócus próprio, onde a arte de governar tem o seu imperativo e a arte de fazer política se constitui na arte de normatizar a vida social: no interior do contexto Legislativo. Desse modo, para se institucionalizar tem origem nas práticas da sociedade mais ampla, considerando as variações formativas dos sujeitos nos âmbitos do direito, da medicina, da engenharia, da teologia, ou de qualquer outra, que serão preponderantes para a legitimação do universo discursivo do político. Cada uma dessas formações, com sua respectiva linguagem, também institucionalizada pelo seu campo formativo, contribuirá para a formação do campo da linguagem discursiva do político. Cada uma com os seus "jargões profissionais de juristas, teólogos, filósofos, comerciantes, e todos aqueles que, por alguma razão, se tornaram reconhecidos como integrantes da prática política e entraram para o discurso político" (POCOCK, 2003, p. 31), funcionando para dar legitimidade e autoridade à configuração da linguagem política, que produzirá o que pode ser chamado de comunidade discursiva legislativa. Importa informar que a formação dessa comunidade, mesmo se dando de forma diversa, tem na origem das linguagens "da prática profissional, que, por alguma razão, entraram na linguagem política e se tornaram idiomas nos quais o discurso político", tem o seu ponto de realização preponderante e articulador do fazer acontecer o discurso político (POCOCK, 2003, p. 70).

Para dar sentido e ao mesmo tempo exemplificar essa chave de leitura, tomaremos como referência um personagem político que transitou no cenário político em Minas Gerais na virada do século XIX para o século XX.

Trata-se de Virgílio Martins de Mello Franco, deputado e senador ${ }^{7}$ do estado, formado no Ensino Superior em Farmácia, na Faculdade de Farmácia, na cidade de Ouro

\footnotetext{
${ }^{7}$ O Congresso Legislativo de Minas Gerais foi organizado, conforme a Constituição de 1891 (Art. 9o, Parágrafo único), pelo sistema bicameral, isto é, de duas Câmaras: a dos Deputados e dos Senadores.
} 
Preto, no ano de 1856 e, em Direito, na Faculdade de Direito de São Paulo, em 1866 . Já havia exercido os cargos de Promotor Público, em Paracatu, e de Juiz Municipal no Termo de Bagagem, Comarca de Patrocínio. Promovido a Juiz de Direito, serviu em diversas comarcas da Província de Goiás e nas mineiras de Rio Novo e Barbacena. Além disso, exerceu o magistério em Barbacena e foi um dos fundadores do Ginásio Mineiro, em Belo Horizonte, onde exerceu também o cargo de Reitor. Mais tarde, foi professor catedrático da Faculdade Livre de Direito de Minas Gerais, tendo lecionado Direito Civil, Direito Internacional Privado e Enciclopédia Jurídica. Cumprido mandato de Deputado Provincial, na 22a legislatura (18781879) e na Câmara do Império na 17ạ Legislatura (1878-1880).

Instaurada a República, elegeu-se Senador Constituinte Mineiro para a 1a Legislatura (1891-1895), tendo feito parte da comissão de onze parlamentares incumbida de elaborar o projeto da Constituição Estadual. Era escritor, tendo publicado o livro Viagens para o interior de Minas e Goiás, em 1888. Como herança de político, seu filho Afrânio de Mello Franco foi Deputado Estadual e Federal, seu genro Honorato Alves, também Deputado Estadual e Federal, além de seus netos Virgílio Alvim de Mello Franco que foi Deputado Estadual e Afonso Arinos de Mello Franco também teve participação na política como Deputado.

É com essa formação de jurista e a realização profissional de magistrado que o sujeito do discurso Mello Franco levou para a Câmara de Deputados e, também para o Senado, uma retórica discursiva de Bacharel em Direito. Dessa forma, o discurso político do senador carregava consigo o lugar de sua formação e de sua profissionalização de homem da lei, e será dessa forma que exercerá naquele campo de forças a legitimidade de jurista, fazendo um uso retórico discursivo a partir desse lugar de pertencimento, de onde se originou o seu discurso.

\footnotetext{
${ }^{8}$ A Faculdade de Direito de São Paulo, no século XIX, se constituiu como um importante centro de formação de uma inteligência política para o Brasil, particularmente para o estado mineiro (SCHWARCZ, 1995; ADORNO, 1988). O objetivo daquela instituição, segundo Sérgio Adorno, era, além de formar o profissional da área, formar lideranças políticas para os diversos campos da vida pública, de modo a estarem aptos a enfrentar os desafios do Brasil como nação, traçando seus rumos pelo império das leis. Essa assertiva já tinha sido anunciada por Rui Barbosa, em 1908, por ocasião de sua visita à Faculdade, quando afirmou que "o mundo acadêmico e o mundo político se penetravam mutuamente" (BARBOSA, 1909, 159). Dessa forma, não é sem sentido a expressiva tese de Adorno, quando vai afirmar que quem passava pela Faculdade de Direito era considerado um "aprendiz do poder".
} 


\section{Geração}

Geração é uma chave de leitura que precisa ser considerada quando o historiador se propõe a conhecer o sujeito do discurso que participa da vida pública, especialmente ocupando o espaço político do Legislativo, portanto fazendo leis com intuito de intervir na vida das pessoas. Trata-se de um conceito que diz respeito à solidariedade das idades (efeitos da idade e fenômeno das gerações) (SIRINELLI, 2003), ao "fenômeno coletivo, partilhado por grupos inteiros que se reclamam dos mesmos postulados e viveram as mesmas experiências", conforme sinalizou Berstein (1998, p. 360). O intelectual precisa ser captado na sua relação geracional, pois ele estará "submetido à mesma conjuntura" da sua geração, "vivendo numa sociedade com normas idênticas, tendo conhecido as mesmas crises no decorrer das quais fizeram idênticas escolhas", pertencente a um grupo que partilhou de "uma mesma cultura política". Tudo isso implicará ou determinará comportamentos solidários de uma mesma época. (BERSTEIN, 1998, p.361).

Retomando o político Virgílio Martins de Mello Franco, destacamos que ele viveu um período geracional que atravessou a abolição da escravatura e a Proclamação da República. Já vinha, como os personagens ilustres da política Afonso Pena, João Pinheiro, Silviano Brandão, Cesário Alvim, Olinto Pires, Augusto de Lima, Bias Fortes, somente para citar os que são mais conhecidos, partilhando das experiências tanto na Monarquia, quanto na República. Inclusive, ele, juntamente com Afonso Pena, se proclamava monarquista, até mesmo depois da mudança de Regime Político. Foi João Pinheiro da Silva, quando Presidente do estado em 1890, quem o indicou as eleições ao senado para fazer parte dos constituintes que elaborariam a Constituição do estado.

Importa, ainda, mencionar a participação de Mello Franco na criação da Faculdade Livre de Direito de Minas Gerais, em 1892, ao lado de vários outros políticos e intelectuais, dentre os quais aqueles mesmos que compunham a sua rede de sociabilidade, como Afonso Pena, João Pinheiro, Silviano Brandão, Olinto Pires, Augusto de Lima, além de seu filho Afonso Arinos de Mello Franco. Nessa Faculdade foi lente catedrático da $2^{2}$ cadeira de Direito Civil.

Ainda, partilhando da sociabilidade com os intelectuais mencionados, dentre outros, foi escritor da Revista da Faculdade Livre de Direito de Minas Gerais. Escreveu vários 
artigos sobre Direito Civil. Também publicou um livro intitulado Viagens pelo interior de Minas Gerais e Goiás, em 1888.

No Senado estadual, compôs com o grupo majoritário de formandos em Direito, de 11 senadores que também formaram na mesma Faculdade de Direito de São Paulo. Além disso, era um dos dezessete senadores, num grupo de 24, com Curso Superior, acrescentando mais três rábulas, advogados práticos. Desses 24 , onze exerceram a docência no Ensino Superior (Direito, Farmácia ou Engenharia) ou no Ensino Secundário, nos ginásios. Foi por várias vezes eleito membro da Comissão de Instrução Pública.

\section{Vínculo de pertencimento familiar}

O pertencimento familiar é também uma chave de leitura considerada. Segundo Cid Rabelo Horta (1986) a linhagem familiar política, ao longo dos séculos XIX e XX, se amalgamou em laços familiares, as quais seriam as controladoras da chefia política mineira. Eram, segundo ele, "os homens bons" que se tornariam ao longo do tempo a amálgama social que se estabilizaria, alargando o poder político e econômico em Minas e no Brasil, por meio do cruzamento dos laços de parentesco entre filhos, genros, netos, sobrinhos formando o que irá chamar de padrões de solidariedade. Para Cid Rabelo Horta,

a história política de Minas é, pois, num largo sentido, a história de suas grandes famílias que fazem o jogo da cena política desde a Colônia". [...] "Constituídas do entrelaçamento de três e mais "famílias nucleares", as "famílias extensas" mineiras formavam como que círculos endogâmicos. Cada círculo era a área social de uma vasta parentela contígua num largo domínio de terra. Num círculo, por mais fechado que fosse, sempre apareceria um membro mais ousado que ia ligar-se, por laços de casamento, com outro círculo socialmente vizinho. Formou-se, [...] uma verdadeira cadeia de círculos familiares, ou parentelas, cujos membros ora se sucediam nas tarefas da chefia política local e regional, ora se alternavam. (RABELO, 1986, p. 1123)

Ele denominou todo esse movimento familiar detentor do poder político de "a constelação governamental de Minas Gerais". Não somente em Minas, vários políticos, presidentes, secretários, deputados e senadores foram se tecendo numa rede de sociabilidade familiar, formando uma cadeia sucessiva de avôs, pais, irmãos, tios, sobrinhos, parentelas que foram se revezando nos mandos políticos.

No nosso caso, Virgílio Martins de Mello Franco era pertencente a familiares em cuja linhagem encontram-se avô, pai, filho, irmão, toda descendência familiar no mando 
político local, regional e em todo estado mineiro. Filho do Tenente da Guarda Nacional, José Martins Ferreira e de Antônia de Mello Franco. Foi o sobrenome de sua mãe que the deu projeção e o constituiu como herdeiro de uma longa família política hegemônica que, por mais de cem anos ocupou postos chaves na República mineira e brasileira. Ela descendia de família portuguesa radicada no Brasil e seu pai foi Francisco de Mello Franco, poeta, formado em Engenharia, Coronel da Guarda Nacional em Paracatu e Deputado Geral do Império. Nessa descendência ou solidariedade parentesca, ele deixou como herança política, seu filho, como vimos, além de seu genro e netos.

\section{A retórica discursiva}

O discurso que proferia o senador Mello Franco, no espaço do Legislativo, era um discurso retórico, por isso precisa ser entendido em dois aspectos que se inter-relacionam: era um discurso político e proferido por um bacharel em Direito. Nesse sentido, como já visto, um discurso político tem seu argumento legitimado pelo lugar de sua produção, pelos sujeitos envolvidos e pelo seu auditório, isto é o lugar de sua pronunciação e seu público. 0 discurso retórico político precisa ser tomado como uma ação política que tinha ou tem como fim a organização da sociedade por meio da intervenção normativa. Isso é o que vamos encontrar no discurso do senador Mello Franco.

Em seu discurso de apresentação do projeto de lei, que viria a se tornar a primeira lei da instrução pública ${ }^{9}$ republicana mineira, em 1892, e que fora aprovado na Câmara dos Deputados, faz como veremos, uma digressão discursiva a partir de um elogio ao trabalho desenvolvido pelos Deputados, de forma prolongada, analisa o texto e interfere nos pontos que considerou problemáticos, chamando a atenção para o que, no seu entender, deveria ser uma proposição de instrução que promoveria a civilidade. Assim expressou:

não posso deixar de manifestar sentimentos de aplauso e encômios à ilustre Comissão da Câmara dos srs. Deputados, e àquele ramo do poder legislativo, que colaborou, organizou e votou o projeto.

Por ele se vê que é crença da Comissão que, sendo convertido em lei, será um grande fator de progresso para nosso estado.

\footnotetext{
${ }^{9}$ Trata-se de um discurso em nome da Comissão de Instrução Pública do Senado, apresentando o projeto de lei que propunha a reforma da instrução no estado de Minas Gerais. Tal projeto tramitou no Congresso Legislativo de setembro de 1891, dois meses após a decretação e promulgação da Constituição do estado de Minas Gerais, até agosto de 1892, quando a Lei no 41, de 3 de agosto de 1892, foi sancionada de pelo Presidente do estado. É uma lei ampla e complexa por contemplava os vários níveis da instrução pública (primária, secundária, superior e profissional) e por ter que se adequar às novas formas de organização da República.
} 
[...] Prevaleceu no espírito da comissão um pensamento geral, que a reorganização do país e o seu engrandecimento futuro dependem da iluminação do espírito das massas.

Costuma-se dizer que a instrução pública é o fator mais direto e mais poderoso na obra progressiva da civilização; mas convém atender-se que a instrução é um simples instrumento de que se pode fazer bom ou mau uso e não convém isolá-la no meio circundante em que o povo vive; mas dá-la de acordo com o estado atual do desenvolvimento social, porque não é possível assim, de chofre, alterar o estado de civilização. (MELLO FRANCO. 1892, p. 1038-1039).

Como se vê, o estilo do discurso apresentado pelo senador demonstra a sua eloquência, num clima de formalidade e de rigidez vocabular, esmerando-se no uso de uma linguagem estritamente erudita. Por conhecer o seu público, que são os senadores, ele sonoriza no seu discurso os argumentos escolhidos, sobretudo de elogios e valorização, como forma de tornar pessoal o pronunciamento e chamar para si os que lhe ouviam. Essa busca de eficácia na argumentação tornou-se possível por saber quem e o que fazia o seu auditório.

Do ponto de vista da formalidade de apresentação de um projeto de lei que estava sendo posto no plenário para ser discutido, o argumento de convencimento precisava vir acompanhado de uma erudição necessária, pois naquele momento, não estava em jogo somente o cumprimento do dever de relatar, mas um jogo político que envolvia negociações e convencimento para que suas ideias refletissem o eco desejado. Por esse motivo, o uso da retórica se fazia necessário, pois seria ela quem daria o protocolo comunicacional propício para o desenvolvimento das articulações políticas.

Assim, o esmero das características retóricas fora utilizado, a saber: a autoridade de orador (bacharel em Direito, relator da Comissão de Instrução, a citação de autores); a argumentação fora procedente, pois não estavam na pauta os valores pessoais (poderia estar fora da pauta) ou os princípios indeterminados de qualquer grupo, mas as ações políticas que envolviam o orador e seus ouvintes; relacionado ao anterior, o conhecimento do público. Esse conhecimento é definidor da escolha do argumento, do estilo da linguagem e da sua pronunciação falada ou escrita (CARVALHO, 2000).

Na sequência do seu discurso, Mello Franco continuou dizendo: "Na vida tudo obedece às leis imutáveis; a evolução mental da humanidade subordina-se as mesmas leis. Natura non facit soltum". Tal argumento, desenvolvido pelo senador, tinha como base a 
teoria de Darwin sobre a seleção natural ${ }^{10}$, na citação que fez em latim: natura non facit soltum (a natureza não faz saltos). O que quis dizer sobre a mutação das leis naturais era que - legislador deveria tomar a prudência como condução do emprego das mudanças propostas, calculando o grau que deveria empregar na aplicação da proposição da reforma da instrução, tendo no estado adiantado do povo a referência principal. Com isso, ele criticava a proposta, considerando-a deslocada da realidade da população mineira, uma vez que não via como possível aplicar um programa de ensino aparatoso com base na instrução europeia, sem levar em conta o estado de adiantamento da população que, para ele, era atrasada, rude e ignorante, conforme aludiu:

Não é possível, pois, adaptarem-se ao espírito inculto das massas populares os programas bem combinados do ensino europeu.

Um povo atrasado, rude e ignorante não pode receber a instrução compatível com as aptidões de um povo já civilizado.

Ridícula será, pois, a tentativa de adoção de processos inaplicáveis a populações atrasadas. (MELLO FRANCO, 1892, p. 1039).

Para lançar mão do recurso da autoridade e, ainda, adensar o seu argumento, cita de Herbert Spencer ${ }^{11}$ que diz: "o legislador é como o médico que deve fazer o diagnóstico e o prognóstico da enfermidade. Assim é que deve medir a força do agente de que vai lançar mão e os efeitos que deve produzir". Esse recurso discursivo reafirma a sua crítica ao projeto que considerava inaplicável ao contexto mineiro. Tudo contribui para o entendimento de que, para ele, a Câmara não havia levado em consideração o prognóstico e o diagnóstico, isto é, não levou em consideração a realidade da população mineira, por isso falhou no diagnóstico.

Na sequência, ele elenca os argumentos para fazer a defesa da sua opinião sobre a norma que deveria intervir na vida das pessoas e da sociedade por meio da instrução. Num primeiro momento, utiliza-se de um axioma para relacionar o mestre ao carrasco e a escola

\footnotetext{
${ }^{10}$ A citação foi baseada no livro "A origem das espécies", publicado em 1859. Disse Darwin: "como a seleção natural atua somente acumulando variações ligeiras, sucessivas e favoráveis, não pode produzir modificações consideráveis ou súbitas; só pode agir a passos lentos e curtos". Esta teoria torna fácil de compreender o axioma: Natura non facit saltum, que cada nova conquista da ciência mostra logo todos os dias ser verdadeiro. (DARWIN, 2003, p. 535.)

${ }^{11}$ Herbert Spencer (1820-1903) foi um filósofo inglês que se tornou um dos principais representantes do evolucionismo darwiniano nas ciências humanas. Escritor de vários livros, dentre eles, muito lido pelos propositores da instrução no final do século XIX, A Educação Intelectual, Moral e Física (1863) e Origem das Profissões s/d.
} 
a prisão: "a criação de um mestre é a supressão de um carrasco e a criação de uma escola, a supressão de uma cadeia" (MELLO FRANCO, 1892, p. 1039). A relação que ele estabelece, sendo jurista, é entre a instrução e a criminalidade. A primeira como prevenção da segunda. Era dessa maneira que a Criminologia do seu tempo compreendia a forma como se poderia eliminar a vadiagem e a ociosidade, pois eram vistas como propensoras à delinquência. A instrução escolar, notadamente a que forma para o trabalho, seria como o lugar do desvio da marginalidade, antes que fosse preciso o investimento da regeneração, na cadeia.

Mas a instrução, entendida como forma de iluminação da consciência das massas, ainda não era por si só suficiente para produzir o desvio desejado. Era preciso, segundo ele, uma educação que "fortificasse o caráter" das crianças. O que ele preconizava era uma educação moral, conforme afirmou: "o projeto cogita mais da instrução do que da educação; entretanto, sabemos que é pela formação do caráter que o homem tem importância na sociedade". Ampliando o seu argumento, irá dizer que não era "a instrução em vasta escala, em edifícios de luxo, com programas", que iria remover "o perigo ameaçador para a sociedade, isto é, a ignorância grosseira das massas inferiores de onde nascem a desordem, a miséria e o crime". (MELLO FRANCO, 1892).

\section{Considerações finais}

O discurso político proferido por um sujeito que ocupa o lugar do mando, não é neutro e nem mesmo encerra em si uma retórica evasiva. Trata-se, portanto, de defesa de ideias e intencionalidades que visam intervir na sociedade de forma a estabelecer normativas reguladoras das vidas das pessoas.

$\mathrm{Na}$ análise que fizemos do discurso do senador Mello Franco, vimos que ele discursava defendendo uma proposição normativa, e o fazia a partir de um lugar posicionado na vida social; ademais, o conteúdo que permeava o seu discurso era carregado de influências que tinha a ver com a sua formação, pois era ela quem seria parte importante para a montagem retórica dos seus argumentos. Nesse âmbito, os formados no Ensino Superior, notadamente no Direito, Medicina e Engenharia, ocupavam os cargos centrais do poder de mando, propondo mudanças e continuidades a partir dos lugares de suas formações e seus discursos reproduziam esses lugares. Tinha a ver também com o seu pertencimento familiar, pois como vimos a perpetuação genealógica das famílias mineiras indicavam a permanência de nomes e sobrenomes nos lugares de mando, num 
revezamento, de geração a geração, num contínuo de representatividade e representação de um status de poder, pertencimento e permanência.

O que se propôs ao longo do texto foi demonstrar que a análise do discurso político, no âmbito da produção do conhecimento histórico sobre a educação e a educação profissional, precisa ser precedida pelo entendimento de que um texto traz consigo um discurso, que é político; e como tal contém história e historicidade, portanto visa intervir na vida social. Associado a esse entendimento, o historiador da analisa do discurso, instrumentalizado por chaves de leitura, poderá captar o processo de produção do discurso, a partir do conhecimento do sujeito do discurso, para enfim, compreende-lo como uma produção sócio-histórica.

Em síntese, reafirmamos que para analisarmos o discurso político precisamos levar em conta não somente o discurso em si, mas o processo de sua produção. Para isso, ele precisa ser entendido na sua historicidade, considerando o sujeito que o produziu, nos aspectos relacionados, à origem e pertencimento familiar, à formação e profissão e suas relações geracionais.

\section{REFERÊNCIAS BIBLIOGRÁFICAS}

ADORNO, Sérgio (1988), Os aprendizes do poder: bacharelismo liberal na política brasileira, Rio de Janeiro, Paz e Terra

BARROS, José D'Assunção. História política, discurso e imaginário: aspectos de uma interface. História SAECULUM. Revista de História, João Pessoa: Universidade Federal da Paraíba, n.12, p. 128141, jan./jun. 2005.

BARBOSA, Rui. Discurso. In: Revista da Faculdade de Direito de São Paulo. p. 159. 1909.

BERSTEIN, Serge. A cultura política. In: RIOUX \& SIRINELLI (Org.) Para uma história cultural. Lisboa: Estampa. 1998.

CARVALHO, José Murilo. História intelectual no Brasil: a retórica como chave de leitura. Topoi, Rio de Janeiro, no 1, p. 123-152. 2000.

CHARAUDEAU, Patrick. Discurso político, São Paulo: Contexto, 2008.

COSTA VAL. M. da G. Redação e textualidade. Martins Fontes: São Paulo.1991.

DARWIN, Charles. A Origem das Espécies, no meio da seleção natural ou a luta pela existência na natureza, 1 vol., [tradução de Joaquim da Mesquita Paul]. Porto: Lello \& Irmão - Editores. 2003.

GINZBURG, Carlo. Mitos, emblemas e sinais: morfologia e história. São Paulo: Companhia das Letras, 1989. 
HORTA, Cid Rebelo. Famílias governamentais de Minas Gerais. Análise \& Conjuntura. Belo Horizonte, 1 (2): pp. 11-142, mai/ago, 1986.

KOSELLECK, Reinhart. Futuro passado: contribuição à semântica dos tempos históricos. Rio de Janeiro: Contraponto: Ed. PUC-Rio, 2006.

LE GOFF, Jacques. História e memória. Campinas: Editora da Unicamp, 1992.

MAINGUENEAU, Dominique. Análise de textos de comunicação. Trad. Cecília P. de Souza-e-Silva e Décio Rocha. São Paul: Cortez, 2013.

MELLO FRANCO, Virgílio Martins de. Anais do Senado. Ouro Preto: Imprensa Oficial, 1891.

MELLO FRANCO, Virgílio Martins de. Anais do Senado. Ouro Preto: Imprensa Oficial, 1892.

MINAS GERAIS. Constituição Política do Estado de Minas Gerais. Outro Preto: Imprensa Oficial, 1891.

ORLANDI, Eni Puccinelli. Texto e discurso. Organon, Rev. do Inst. Letras/UFRGS, Porto Alegre, v. 9, n. 23, p. 111- 118. 1995.

ORLANDI, E. P. As formas do silêncio: no movimento dos sentidos. 3. ed. Campinas: Ed. Unicamp, 1995. 189p.

ORLANDI, Eni Puccinelli. Análise de Discurso, Princípios e Procedimentos. São Paulo: Pontes, 2001.

POCOCK, Greville Agard. Linguagem do ideário político. São Paulo: Editora da Universidade de São Paulo.

SCHWARCZ, Lilia Moritz. O espetáculo das raças: cientistas, instituições e questão racial no Brasil 1870-1930. São Paulo: Companhia das Letras. 1993.

SIRINELLI, Jean-François. Os intelectuais. In: RÉMOND, René. Por uma história política. Rio de Janeiro: Editora FGV, 2003. 